The Turkish Online Journal of Design, Art and Communication - TOJDAC

ISSN: 2146-5193, September 2018 Special Edition, p.1016-1023

\title{
OPTIMIZATION OF EDUCATIONAL PROCESS IN HIGHER EDUCATION INSTITUTIONS: MODERN TRENDS AND PROSPECTS
}

\author{
Olga V. STUKALOVA \\ Institute of Art Education and Cultural Studies of the Russian Academy of Education, Russia
}

\begin{abstract}
The purpose of the paper is to reveal modern trends and prospects of optimization of the educational process in higher education institutions. The system-forming elements and principles of optimization of the educational process in higher education institutions are highlighted, including the principle of passive and active consideration of factors of quality of education; the principle of expanding the composition of factors of quality of education; the principle of combination of factors of quality of education; the principle of monitoring the quality of education in real time; the principle of supporting the positive dynamics of quality of education. The role of organizational matrices based on goalsetting and domination of horizontal coordination of interaction of creative groups, whose tasks include research projects, is shown. A model of optimization of the educational process in higher education institutions, tested during many years of practice in various Russian higher education institutions is developed. The structure of this model includes such components as predicting the results of the implementation of models; monitoring the quality of the educational process; analysis of the prospects for the development of educational organizations; diversification of the educational process; reliance on effective tools for improving the competitiveness of a higher education institution. It is proved that as a result of the implementation of the model in the educational process of a higher education institution the practice-oriented content of education adequate to the modern requirements of the society is implemented. The analysis of experimental work in higher education institutions is given.
\end{abstract}

Keywords: Higher Education, Matrix, Horizontal Coordination, Professional Training, Optimization, Goal Setting, Diversification

\section{INTRODUCTION}

Optimization of the educational process in a higher education institution is a multilateral phenomenon that requires the expansion of the spheres of pedagogical activity, the creation of a variety of educational services, the development of new types of professional specialization. It is obvious that the optimization of the educational process in a higher education institution involves a multi-level professional training of future specialists, relying on the idea of spectrum and diversification, which requires an increase in the functions of educational institutions, the creation of variable educational programs, etc. Thus, the optimization of the educational process meets the requirements of the new paradigm of higher education, which is characterized by increased flexibility of the whole system, ready for rapid changes and the desire to continuously improve the quality of professional training of future professionals capable of designing their personal and professional implementation (Neubauer, 2010).

The analysis of the interpretation of the theoretical provisions on the essence of the optimization of the educational process in a higher education institution shows that:

1) modern researchers associate these provisions with the vision of the global educational space, in which the transition to innovative structures in education which rejects the unified construction of the educational process (Alekseeva, 2018);

2) consideration of the optimization of the educational process takes place in the context of modern trends of education reform in the multicultural information society and the relevant reality of educational policy (Tatur, 1992);

3) optimization is considered as a basis for improving the educational process, which creates conditions for mastering the ways of cognitive, practical and social activities, immanently

Submit Date: 11.07.2018, Acceptance Date: 24.08.2018, DOI NO: 10.7456/1080SSE/140

Research Article - This article was checked by Turnitin

Copyright (C) The Turkish Online Journal of Design, Art and Communication 
contributing to the creative-active and socially significant formation of personality (Galagan, Polyanskaya 1998).

Scientists note that optimization is "... the most important trend in recent years, which will determine the formation of the academic system" (Altbach, 1992); that on its basis, as well as on the basis of the principles of diversification, it is possible to create a flexible system of education that can respond to the challenges of the labor market (Smirnov, 1991). The studies (Hysen, 1992, Shevaje, 1993, Asher Johnston 1995, etc.) identified conditions for stimulating the process of self-discovery, development of creative thinking, professional competence, etc.

In a number of works, the methodology of education optimization (Baidenko, 2015, etc.) is developed and the characteristics of this process are revealed, including:

- the desire for continuous development of an integrated educational system;

- the impulse for the development of innovative pedagogical technologies (Stukalova, 2017), multivariate educational programs;

- reliance on the position of personality-oriented and system-activity approaches;

- creation of conditions for the productive disclosure of individual abilities, opportunities and needs of each individual.

The need to optimize Russian higher education is determined by the needs of the modern social situation, which is characterized by a combination of the economic development of society and culture.

The works of contemporary scientists (Kudrin, 2014, Munger, 2008) considered the criteria for the evaluation of training, presented the profile programs of specialists, identified the qualifying models. It is emphasized that new specialties are being introduced, which require the development of innovative programs and the expansion of the range of training courses, especially in the field of information and computer technologies and management.

In theoretical aspect, the following directions of optimization of the educational process were identified:

- optimization of forms of educational process;

- profile optimization, during which the opportunities of choosing the profile of the educational organization, are expanded;

- didactic optimization, including the development and implementation of modern technologies and methods of training, based on the developed didactic development systems of training (Zankov, 1968; Davydov, 2000; Sidon, 2014), the idea of "dialogue of cultures" (Bibler, 1996);

- optimization of information systems of educational organizations. This includes optimizing the implementation of the educational potential of multimedia tools (Martensson, Roxa, 2016).

The most productive is a holistic system optimization of the educational process (Mukhudadaev, 2003: 405). In the course of the system optimization, the quality of education is monitored fairly objectively, which increases the rating of the higher education institution, stimulating the development of the range of educational services, directions and specifications of training. The importance of connecting horizontal and vertical vectors of optimization of the educational process in the higher education institution should also be highlighted: this contributes to the creation and development of the variable part of the educational process, on the one hand, and flexible implementation of the requirements of the state standards of the invariant part, on the other. 
In the article, a model of optimization of the educational process in the higher educational institution is theoretically justified, which is based on the certain organizational matrix, based on 1) rational goal setting; 2) the priority of horizontal coordination of the interaction of different structures and substructures of the educational organization. In this case, a higher education institution creates mobile creative groups that develop research projects. The advantages of this type of organizational matrix are: a) decentralization, b) delegation of authority; c) division of areas of responsibility - all this stimulates the development of the higher education institution, increasing the level of internal motivation and readiness to be responsible for key decisions in all subjects of the educational process.

In the process of implementation of the model, it is necessary to change the structure of higher education management, integrating it into the system of continuing education. The introduction of this model in the educational process allows organizing professional training in higher education more systematically, logically, orienting it to a meaningful and thoughtful achievement of the final result, taking into account the goals and logic of each stage. It is also possible to note the possibility of forming a stable professional self-determination of students. The goal of optimization in this context is to stimulate the desire for continuous personal and professional growth. The effectiveness of training, in this case, becomes one of the most important indicators of the quality of the educational process and is expressed in the close cooperation of the higher education institution and the prospective employer. It is obvious that such cooperation allows planning more accurately ways of further employment of graduates, solving the actual problem of employment (Price, Kirkwood, Richardson, 2016).

The optimization of the educational process in the higher education institution on the basis of the organizational matrix structure also allows creating conditions for the enrichment of professional and $\mathrm{m}$ jcommunicative experience, the disclosure of their creative potential (Akishina, Sudakova et al., 2017). Thus, future specialist gets a chance to more organically and quickly adapt to the rapid pace of changes in living conditions and the growth of professional requirements. This should be attributed to the leading trends in the optimization of education in higher education institutions. Therefore, optimization is one of the manifestations of higher education reform as a continuous process, when a person develops and improves his/her personal creative potential throughout life, without destroying the continuity of all levels of education (Olesina, Stukalova, 2015).

At the same time, the difficulties hindering the efficiency of optimization are also obvious. First of all, they are distinguished as follows:

- limited options for higher education that do not meet the requirements of the development of continuing education in the current social and economic situation (Cruz, 2014), (Cretchley, Edwards, O'shea, Sheard, Hurst et al., 2013: 649 - 669), (Fitzpatrick, Moore, 2013), (Leibowitz, Bozalek, van Schalkwyk, Winberg, 2014);

- enhanced standardization of education, which does not allow to expand the range of educational services, meeting the requirements of modernization of vocational training;

- difficulty in enabling each student to choose their own educational path based on individual request and conditions of employment in the region (Lazarev, Podvoisky et al., 2016).

- The model of optimization of the educational process in higher education institutions presented in the paper is aimed at solving the distinguished difficulties.

\section{THE RELEVANCE OF THE STUDY}

The formation of a qualitatively new level of thinking and innovative lifestyle of the future specialist in the course of professional training at a higher education institution requires a structured system optimization of the educational process, which takes into account scientific approaches to the problems of pedagogical impact on professional self-determination of an individual and the development of internal motivation for professional growth. The educational process at a higher education institution requires the development of a single methodological framework. Optimization of the educational process at the higher education institution is aimed at bridging the gap between the dynamic socio-economic development of society and the system of higher education, which does not 
have time to adapt to the rapid pace of reforms, to respond quickly to the need to introduce new educational services.

The development of the model is aimed at the effective transition of the educational process in higher education institutions to innovative pedagogical technologies, which involves the reliance on the organizational matrix of the horizontal interaction of creative groups working on research socially significant projects. Also, during the study, special variable educational programs for the development of social and cultural projects were created on the basis of interaction with non-profit public organizations and charitable foundations: work with children in difficult situations, etc. These programs took into account the possibilities of partnership in the development of the volunteer movement.

\section{MATERIALS AND METHODS}

Testing of the model of optimization of the educational process was carried out in the following modern Russian higher education institutions: Moscow State University of Culture and Arts (Moscow State Pedagogical University), Moscow State Institute of Culture; National Nizhny Novgorod State University named after N.I. Lobachevsky (Arzamas Branch of Nizhny Novgorod State University); Smolensk State Institute of Arts. The study covered 2011-2018. Criteria and evaluation system of education quality monitoring was developed.

The developed model of optimization of the educational process in the higher education institutions is based on a) representation of the educational process as a whole dynamic phenomenon, for the structuring of which the target distribution of available resources (personnel, material, information) is significant; b) methodological provisions on the inextricable relationship of General and professional development of an individual. The model implies the implementation of regular feedback, which ensures the effectiveness of pedagogical support. The structure of this model is multicomponent and includes such components as predicting the results of the model's implementation; monitoring the quality of the educational process; analysis of the prospects of the educational organization development; diversification of the educational process; reliance on effective tools to improve the competitiveness of the higher educational institution.

The study identified the system-forming elements of optimization of the educational process in the higher education institutions:

- creation of innovative platforms for testing new technologies and methods of higher education;

- comprehensive implementation of innovations recognized as effective in the educational process of the higher education institutions;

- information support taking into account the existing trends of information dissemination and wide use of the potential of Internet resources and social networks;

- constant monitoring of the quality of education in different aspects.

In the educational process, the quality of education was actively and constantly monitored, assessing: the level of professional self-determination of students, the level of information environment of the higher educational institutions, the level of development of the system of training, the level of implementation of the organizational matrix of horizontal interaction of creative groups. The first criterion was evaluated on several indicators: the connection of individual goals with the professional choice; expression of students' value orientations associated with higher education; readiness for professional self-realization.

During the implementation of the model, the following was carried out:

- description and generalization of the activities of innovative platforms; 
- drawing up a roadmap for the development of the site: goals, objectives, specifics and process of the site, its success and difficulties arising in the course of work;

- creation of a database of new technologies and techniques that contribute to the optimization of the educational process;

- pedagogical support of creative groups;

- conducting training seminars for young teachers who want to deepen their knowledge, contributing to their inclusion in the optimization of the educational process;

- information support.

\section{RESULTS}

The dynamics of optimization of the educational process in higher education institutions was studied according to the selected criteria. An example of the generalization of monitoring data is given in Table 1.

Table 1. Assessment of the dynamics of the level of professional self-determination of students (in terms of: "connection of individual goals with the professional choice")

\begin{tabular}{|c|c|c|c|c|}
\hline Indicator & $\begin{array}{l}\text { Moscow State Pedagogical } \\
\text { University (Institute of } \\
\text { Social-Humanitarian } \\
\text { Education; Institute of } \\
\text { Childhood) }\end{array}$ & $\begin{array}{l}\text { Moscow State } \\
\text { Institute of } \\
\text { Culture } \\
\text { (Department of } \\
\text { Socio-Cultural } \\
\text { Activities) }\end{array}$ & $\begin{array}{l}\text { Nizhny } \\
\text { Novgorod State } \\
\text { University } \\
\text { (Arzamas } \\
\text { branch) }\end{array}$ & $\begin{array}{c}\text { Smolensk } \\
\text { State } \\
\text { Institute of } \\
\text { Arts }\end{array}$ \\
\hline \multirow{4}{*}{$\begin{array}{l}\text { Connection of } \\
\text { individual goals } \\
\text { with the } \\
\text { professional } \\
\text { choice }\end{array}$} & $2011-201212 \%$ & $\begin{array}{c}2011-2012 \\
26 \%\end{array}$ & $\begin{array}{c}2011-2012 \\
24 \%\end{array}$ & $\begin{array}{c}2011-2012 \\
26 \%\end{array}$ \\
\hline & $2013-2014$ 18\% & $\begin{array}{c}2013-2014 \\
46 \%\end{array}$ & $\begin{array}{c}2013-2014 \\
48 \%\end{array}$ & $\begin{array}{c}2013-2014 \\
67 \%\end{array}$ \\
\hline & $2015-201638 \%$ & $\begin{array}{c}2015-2016 \\
52 \%\end{array}$ & $\begin{array}{c}2015-2016 \\
51 \%\end{array}$ & $\begin{array}{c}2015-2016 \\
77 \%\end{array}$ \\
\hline & $2017-201864 \%$ & $\begin{array}{c}2017-2018 \\
78 \%\end{array}$ & $\begin{array}{c}2017-2018 \\
75 \%\end{array}$ & $\begin{array}{c}2017-2018 \\
88 \%\end{array}$ \\
\hline
\end{tabular}

The data were obtained during the surveys, testing and pedagogical observation (teachers of the higher education institutions were included in this process). The study covered 1026 students - representative sample, which allows concluding that these results are valid, it can be argued that in the process of optimization the chosen profession becomes more attractive for future professionals, and they more clearly understand the personal importance of education, which corresponds, affects the level. It is also necessary to take into account that high results in the sphere of culture and art are largely determined by the fact that for students of these universities the relationship of personal and professional development in the field of performance and artistic creativity is natural.

It was noted that the impact of optimization is reflected in the fact that students begin to more clearly understand the picture of professional implementation ("professional landscape"), to see the differentiation of specialties, to understand how intermediate professions can become the basis for the manifestation of their own abilities and become the basis for further personal and professional development. There is a more adequate assessment of their capabilities, abilities and a more meaningful approach to their professional implementation. 
An oral survey of teachers of the higher education institutions (150 teachers interviewed) allowed to state the following: most of them $(87 \%)$ are not very clearly aware of the importance of optimizing the educational process, its direction and conditions of implementation, explaining that they do not know modern methodological literature on this issue and do not have sufficient information about the best pedagogical experience; are not ready to be included in the optimization because of the existing workload, etc. On the other hand, it is important to note that teachers agree that the implemented directions of optimization of the educational process in the higher education institutions have a positive impact on the professional development of students.

\section{DISCUSSION}

The obtained results allowed to determine the following significant positions for the implementation of the model of optimization of the educational process in a higher education institution:

1) optimization is a significant trend in the development of the system of continuous education, forming the conditions for the effective use of innovative technologies, taking into account the individual abilities, capabilities and needs of each student;

2) optimization process is based on the integration of a number of components, including: prediction of the results of the models implementation; monitoring of the quality of the educational process; analysis of the prospects of educational organization development; diversification of the educational process; effective tools for improving the competitiveness of a higher education institution;

3) optimization of education in a higher education institution is inextricably conducted in two levels - horizontal, on which the expansion of the range of use of pedagogical and socio-cultural technologies is carried out (Savenkova, 2015), and vertical, which is the improvement of continuous education taking into account the state educational standards;

4) objective reality of the optimization of higher education is the possibility of planning and regulation of this process; in this case, the range of factors of quality of education is significantly expanded; one of the significant results is a high level of professional self-determination;

5) the study revealed the principles of optimization: passive and active consideration of factors of quality of education; expanding the composition of factors of quality of education; a combination of factors of quality of education; monitoring the quality of education in real time; the principle of supporting the positive dynamics of quality of education.

\section{CONCLUSION}

The study revealed:

1. The goal of optimization of the educational process in higher education institutions is the development of the abilities of future specialists and their internal motivation for productive self-realization in professional activities; stimulation of students to professional selfdevelopment; creation of conditions for the enrichment of the creative potential of an individual, the integration of educational and practical activities; consideration of pedagogical features of the structure and content of educational needs of a person at different stages of his/ her life; unity of professional, general and humanitarian education; scientific-methodical and psychological-pedagogical support of self-education of each student;

2. Optimization mechanisms: consistency and continuity in the process of professional development growth; individualization of training; diversity and flexibility of the types, forms and pedagogical technologies used; inclusion in the higher education system of various forms of professional training, including non-formal and non-institutional types of higher education; implementation of the model of optimization of the educational process in higher education institutions; creation of conditions for the fundamentalization of education (Novikov, 1997); integration of modern approaches to the construction of higher education system; socially significant and creative activity character of the educational process; 
3. Factors of productive optimization:

- providing independence in the choice of educational programs in accordance with the needs of society;

- development and implementation of innovative learning technologies covering the main practiceoriented areas of modern human life;

- continuity and staging of organizational and structural reform of the higher education system (Nikitin, 2017).

One of the basic conclusions is the provision that the optimization of higher education allows creating a professional and qualification structure of professional training of specialists, who master the actual practice-oriented content of education, which is implemented in constantly updated educational programs, courses, forms of educational activity. Thus, the implementation of the model of optimization of the educational process in a higher education institution provides the society with highly qualified personnel with a high level of professional self-determination and internal motivation for professional improvement.

\section{ACKNOLEDGMENT}

The results of the study were obtained in the framework of the state task of the Ministry of Education and Science of Russia (27.7394.2017/8.9).

The author expresses gratitude to Ekaterina Mikhailovna Akishina, Candidate of Science (Art history), Director of the Federal State Budgetary Scientific Institution "Institute of Art Education and Cultural Studies of the Russian Academy of Education" for her support of theoretical ideas and promotion of innovations in the educational environment of higher educational institutions $(2016-2018)$.

\section{REFERENCES}

Akishina, E.M., Sudakova, Y.E., Prokopyev, A.I., Yakubenko, K.Y., Solovyeva, N.A., Korzhuev, A.V. (2017). System of cultural experience development of humanities students in modern information media conditions. Man in India, 97(14), 115-127.

Alekseeva, L.L. Sorokoumova, E.A., Vakhrusheva, L.N., Litvinov, A.V., Popovitskaya, N.V., Filipenkova, O.G. (2018). Pedagogical opportunities of student communicative culture development. XLinquae, 1, 203-217. http://www.xlinguae.eu/issue n_ 1_2018.html

Altbach, F.D. (1992). Models for the development of higher education in the eve of 2000. Moscow, Nauka, 14.

Baydenko, V. I. (2015). the Bologna process: the modern stage. Higher education in Russia, 1, 53-58.

Bibler, V.S. (1996). Holistic concept of the school of the dialogue of cultures. Theoretical basis of the program. Psychological science and education, 4, 66-73.

Chewie, J.K., Asher, T. (1993). New approaches to the financing of post-compulsory education. Prospects: Education, UNESCO'S quarterly magazine, 3, 52-55.

Cretchley, P.C., Edwards, S.L., O'Shea, P., Sheard, J., Hurst, J. \& Brookes, W. (2013). Research and/ or learning and teaching: a study of Australian professors' priorities, beliefs and behaviors. Higher Education Research \& Development, 33(4), 649-669.

Cruz, L. (2014). Opposing forces: institutional theory and second-generation So TL. International Journal for the Scholarship of Teaching and Learning, 8(1), 1.

Davydov, V.V. (2000). Types of generalization in training: logical and psychological problems of building subjects. Moscow, Pedagogical society of Russia.

Fitzpatrick, M. \& Moore, S. (2013). Exploring both positive and negative experiences associated with engaging in teaching awards in a higher education context. Innovations in Education and Teaching International, 52(6), 621-631.

Galagan, A.I., Polyanskaya, G.I. (1998). System of the foreign higher schools. Moscow, Research Institute of Higher Education.

Hysen, T. (1992). Idea of a University: evolution of the function, problem. Prospects: educational issues, 3, 23-40.

Johnston, B. (1995). Higher education in the United States in 2000. Perspective: Educational issues. Quarterly journal, UNESCO, 4, 18. 
Kudrina, E.L. (2014). Role of universities of culture and art in promoting the historical and cultural heritage of Russia. Knowledge. Understanding. Skill, 2, 61-73.

Lazarev, M.A. Podvoysky, V.P., Stukalova, O.V. (2016). Pedagogical support of overcoming social indifference of students of humanitarian universities: social and cultural approach-Moscow, MAO, Daugavpils: Daugavpils University.

Leibowitz, B., Bozalek, V., van Schalkwyk, S. \& Winberg, C. (2014). Institutional context matters: the professional development of academics as teachers in South African higher education. Higher Education, 69(2), 315-330.

Martensson, K. \& Roxa, T. (2016). Working with networks, microcultures and communities. In D. Baume \& C. Popovic, Advancing practice in academic development. London: New York: Routledge, 174-187.

Mukhudadaev, M.O. (2003). Differentiation of educational structures of the civil society: processes outline. Innovation and education. Proceedings of the Conference. Series "Symposium". Saint Petersburg, Saint-Petersburg philosophical society, 29, 405.

Munger, T.E. (2008). Mechanisms of diversification of the system of continuous education in the sociocultural sphere. Bulletin of Tambov University. Ser Humanities, 8(64), 23-36.

Neubauer, D. (2010). Ten Globalization Challenges to Higher Education Quality and Quality Assurance. Evaluation in Higher Education, 4(1), 13-37.

Nikitin, O.D. (2017). Pedagogical model of creative development of students of pedagogical universities: monograph. Moscow, Music.

Novikov, A.M. (1997). Professional education of Russia. Moscow, ICPNA Russian authors' Society.

Olesina, E.P., Stukalova, O.V. (2015). Humanitarization of the educational process of training of future teachers: conceptual provisions and prospects. Kazan pedagogical journal, 3, 124-129.

Price, L., Kirkwood, A. \& Richardson, J. T. (2016). Mind the gap: the chasm between research and practice in teaching and learning with technology. In J. Case \& J. Huisman (Eds.), Researching higher education: international perspectives on theory, policy and practice London: New York Routledge, 227-245.

Savenkova, L.G. (2015). Humanization of education and innovative learning technologies. Bulletin of Moscow State University of Culture, 3, 203-211.

Sidon, L.M. (2014). Davydov, V.V. and Zankov, L.V. On the essence of pedagogical theory. Domestic and foreign pedagogy, 3, 116-120.

Smirnov, A.G. (1991). The higher educational system of Western countries. Moscow, Peoples' Friendship University of Russia.

Stukalova, O.V. (2017). System of cultural and creative development of students in the educational environment of higher education institutions in the sphere of culture and art. Espacios, 38(56), 33.

Tatur, Yu.G. (1992). Diversification of higher education in Russia. Moscow, Alma mater.

Zankov, L.V. (1968). Didactics and life. Moscow, Education. 